\title{
Progress and Prospect of Extreme Climate Events in Arid Northwest China
}

\author{
Xiangling Tang ${ }^{1}$, Xin $\mathrm{Lv}^{2}$, Feng Xue ${ }^{3}$, Ying $\mathrm{He}^{4}$ \\ ${ }^{1}$ Geography Department, School of Natural Science, Shihezi University, Shihezi, Xinjiang \\ ${ }^{2}$ Xinjiang Production and Construction Corps Key Laboratory of Oasis Agriculture, Shihezi, Xinjiang \\ ${ }^{3}$ Shihezi Quality Technical Supervision Bureau, Shihezi, Xinjiang \\ ${ }^{4}$ School of the Liberal Arts, Xinjiang Education Institute, Urumqi, China \\ Email: txl_tea@126.com
}

Received October 18, 2012; revised November 21, 2012; accepted December 21, 2012

\begin{abstract}
Extreme climate events have significant influences on ecological systems and social economic systems. The global climate is becoming warmer and warmer, so extreme climate events will probably increase in both frequency and intensity, and the Northwest arid region of China is situated in the middle latitudes, all of which combine to make this area become the most sensitive region to global climate change. For this reason, based on home and broad literature of research in extreme climate events, this paper mainly discusses those scientific problems which are waiting for resolved and we should strength work that those need research in future from extreme climatic events concept, their change regular, the discussion of theory reasons, and review from mode and simulate, as well as sum up some research results related extreme climatic change.
\end{abstract}

Keywords: Climatic Change; Extreme Climatic Events; Arid Northwest Region

\section{Introduction}

In recent hundreds years, the global climate has undergone noticeable changes mainly characterized by warming [1]. The increase in the average temperature not only has a direct influence on the change in the temperature extreme, but also speeds up water circulation, so that there is a drastic increase in the frequency and intensity of extreme climate events such as hot weather, droughts, rainstorms, and floods [2]. Compared with climatic mean states, extreme climate events often exert greater influences on economy, society, and ecological systems [3-5]. China is one of the countries that suffer the most serious natural calamities. From 1993 to 2003, the national economy of China suffered a loss of 210 billion (RMB) due to meterological disasters, which destroy $3 \%-6 \%$ of China's GNP every year [2]. So extreme climate events have drawn the attention of all the national governments and researchers [2,5]. Carrying out research into extreme climate events is not only necessary to guaranteeing national security, developing economy, and preventing and reducing natural disasters, but also has direct bearing on national economy and people's livelihood.

The arid northwest China is influenced by the rise of the Qinghai-Tibet Plateau, the effect of the westerly wind circulation, and the alternation of high mountains and vast basins; zonal mountainous ecosystems, desert eco- systems, and zonal oasis ecosystems interact on each other, carrying out the matter migration and energy conversion process which has water as its driving force, forming the special natural unit whose basic feature is the compound ecosystem of mountain-oasis-desert, so that this region is the most sensitive one because of the global climate change. Due to the joint influence of climate change and human activities, arid areas, with ice and snow melt water as their bases of water resource system, are very fragile. Increases in temperature cause seasonal changes in the runoff of ice and snow melt water, and cause variations of water resource, resulting in the decline of the stability of the water circulation system and the renewability of water, an increase in the uncertainty, and an increase in the frequency and intensity of extreme climate/hydrologic events. For example, in 2006, there were frequent floods in northern Xinjiang and droughts in southern Xinjiang; in 2008, there was incredibly little precipitation in northwest China, which was the most serious drought in thirty years; in the winter of 20092010, there were snowstorms rare in nearly fifty years in northern Xinjiang, resulting in widespread catastrophes such as the snow-slide and disastrous snowmelt floods, therefore, cause at least 500 thousands people were suffered natural disaster; in winter of just past last year 2011, North in Xinjiang has already been subjected to some bad weather such as cold wave, heavy snow etc, and also 
appeared continuous snow storm which occurred once in 60 years, its feature is large rainfall, thick snow, big amplitude of variation on temperature, as well as continuous low temperature and long time snows, as result a number of index exceeded historical limited value. Hydrology events arise from Climatic change aggravate the influence of water supply system in arid region Xinjiang, Northwest China, it also make the oasis agriculture production unstable, so increase safe operation risk for significant project.

With the weather continuous becoming warmer and warmer in global, those extreme climatic events appeared more and more in arid region of Northwest, China, such as low temperature, snow storm, sand storm, strong wind etc [2].

At present, scholars home and abroad are carrying out research into the patterns of the occurrence and evolvement of extreme climatic events in different fields from different dimensions. Therefore, it is of great significance to have a clear idea of the research into extreme climate events, the trends of international research, for the reduction of extreme climate events and the improvement of human ability to adjust and cope with them.

\section{Testing Indexes and Methods of Extreme Climatic Change}

For a specific place and time, extreme climate events are events of extremely little incidence seen from the angle of probability distribution. They usually constitute 10 percent or less of the same kind of weather phenomena; extreme climate events are the mean state of large numbers of climate extremes in a specific period. This average state is also extreme compared with the climate mean state of that kind of weather phenomena [6]. Although there are considerable research results of past extreme climate [7-9]; Alexander et al. [9] it is difficult to compare the results of different researches because of different ways of defining extreme climate, different lengths of time series of the material used, different densities of spatial distribution or types of material, and different trend test methods, etc; it is more difficult to piece together the research results of different regions into a whole to reflect the characteristics of the overall change of regional extreme climate events.

At present, there is a unified standard to study the characteristics of extreme climate change, i.e. extreme climatic index, which is the result of calculating the daily maximum, minimum and mean temperatures or daily precipitation. This method was initiated by the WMO at the climate change conferences from 1998 to 2001 [10]. Alexander et al. [9] classify these indexes into five categories: 1) relative indexes based on threshold in percentage; 2) absolute indexes representing the maximum or minimum value of a certain season or year; 3) threshold indexes of the number of days whose temperatures or precipitations larger or smaller than a certain fixed threshold; 4) duration indexes corresponding with over cold, over hot, over dry, over wet durations or growth cycles in comparison with growing season durations; 5) other indexes, including total precipitation, diurnal temperature range, mean rainy-day precipitation intensity, extreme temperature difference, and the percentage of annual extreme precipitation among total precipitation. These indexes, with their weaker extremity, low noise, and strong significance, can display the changes in the different aspects of extreme climate [11]. These extreme climatic indexes, taking into consideration the intensity and duration of extreme climate events, have been recommended by the European STARDEX plan to describe key indexes related to extreme climate events.

Because of its representativeness in the study of climate extremes, extreme climatic index has been widely used both home and abroad [12,13]; however, most researches concentrate on a certain kind or type extreme climate events but comprehensive research of many kinds or types of extreme climate events in a certain region is not enough [14]. In the test and research of the influence of climate change, it is often necessary to learn about the general change in the frequency and intensity of many kinds of extreme climate events in a certain region or country. Therefore, how to choose from various extreme climatic indexes those of specific climatic and social economic indicative significance, construct a regional extreme climatic composite index, and analyze the past and future trends of change, is worthy of research.

Karl et al. [15] defines a climatic extreme index (CEI) oriented to mainland United States, taking into consideration the index of extreme temperatures and precipitation, which consists of monthly mean maximum temperature, monthly mean minimum temperature, extreme daily precipitation, number of days of precipitation, that of non-precipitation, and Palmer index (PDSI) and analyzed on the basis of yearly and seasonal mean. Gleason et al. [16] revised this index, adding earlier material points and updated the sequence to the year 2006. However, because of the different climate conditions of different regions and countries, their kinds and influences of extreme climate events are also different. Moreover, different climate events have drastically different influences on a region or country while CEI laid on extreme climate events of five indexes the same emphasis. So although the conception of CEI has some value of reference, it cannot be applied to a country or region, and an index of regional value must be constructed according to local needs.

\section{The Feature of Change and Influence of Extreme Climate Events}

Past researches on climate change were mainly focused 
on changes in mean temperatures and precipitation, however, changes in the frequency and intensity of extreme climate events have greater influence on society and the environment [14,17]. Therefore, scholars both home and broad have in recent years attached importance to extreme climate events and achieved a lot. For example, studies indicate that there have been an increase in the frequency and intensity of extreme precipitation events in the middle and higher latitudes of the Northern Hemisphere [2,9], and there is an obvious decrease in the frequency of extremely cold nights related to minimum temperatures but a notable increase in the frequency in extremely warm nights in most terrestrial areas [4,11,17, 18], the droughts in the subtropics of the global land areas are more severe and enduring, the activity of the severe tropical cyclone of the North Atlantic area have increased [2]. In the future, because of the influence of greenhouse effect, there will be a continuous increase in the frequency of heat events, heat waves, and heavy precipitation events [2], and there is a general tendency of rainstorms and droughts to increase and displays an obvious regional difference [2,19].

Extreme climate events in China have strong regional characteristics and more complex and changeable features. Temperature-related indexes have assumed noticeable changes; for example, there is an obvious increase in warm summer nights, an evident decrease in frost days [17]. and a clear trend for daily maximum and minimum temperatures to rise in north China, however, precipitation-related index reflect significant regional disparities or local characters; for example, there is a general trend for rainstorms to increase but it is very slight and there is an obvious seasonal change [20]; there is a very noticable increase in the mean precipitation intensity extreme in east China and the area in which extreme appear is expanding [8], maximum precipitations of five successive days and precipitation events of more than heavy rains have been increasing considerably in many regions $[20,22]$. In the east of northwest China, most of north China and the south of northeast China, there is a major trend of drought and there is also an aggravation of flood in the middle and lower reaches of the Yangtze River and southeast China; in northwest China there is also an increase in the frequency of heavy precipitation events [23].

Most research indicates that the changes in the frequency of temperature-related extreme cold (warm) days (nights) are probably the results of emissions of greenhouse gases; extreme heavy precipitation events in the middle and higher land latitudes of the Northern Hemisphere are also probably the reactions to global warming $[2,22]$. Scholars of all countries have connected the changes in climate extremes to global climate changes. For example, Mearns et al. [24] point out that the mean value change of the original distribution of climate variables may result in the non-linear change in extreme value frequency and intensity; that is, slight changes in the mean climate field will probably bring about major changes in the intensity and frequency of extreme climate events [3]. When the extremity of extreme climate events is relatively considerable (i.e. departing from the mean value for over 1 standard deviation), the sensitivity of the variance to mean value frequency will be much significant than that of the mean value to the extreme value frequency. China's extreme climate change of the recent 50 years can be 5 to 10 times that of mean climate change, but the mean climate change of some sites is not considerable while the reverse phase change of extreme climate is [25], so mean climate can hardly describe the actual process of climate change [2], and it is necessary to carry out research into the relationships between climate change and statistics distribution of climatic extremes, mean climate statistical parameters and extreme climate statistics distribution. China's abnormal climate is due mainly to constant abnormal large-scale atmospheric circulations. Under the background of global warming, a very important reason for regional climate change is the variation and adjustment as a result of the reaction of atmospheric circulations to global warming [26].

Northwest China, consisting of Xinjiang, Gansu, Qinghai, Ningxia, Shaanxi and the west of Inner Mongolia, lies on the north and northeast of the Qinghai-Tibet Plateau. Its location in the center of a continent, its great distance from ocean, and the topographic action of the Qinghai-Tibet Plateau have resulted in the dry climate of this part of China, while the action of heat and movement of plateau topography and the inter-annual change in prevailing circulation bring about the change of relatively dry and wet years in arid regions. Qian et al. offer their circulation chart of the summer vertical circulation chart of Qinghai-Tibet Plateau and its surrounding regions, graphically showing that there exist downdraft areas on the north and northeast sides, which coincide with China's northwest arid and semiarid regions. The deserts, gobi deserts, and exposed underlying surfaces react quickly to the heat of sunlight, resulting in strong surface evaporation potential, thus aggravating the acidification. Global changes have a profound influence on the changes in northwest China's climate and ecological environment. This region's climate system has a complicated composition, and the external forcing of global climate change usually bring about drastic changes in the climate system in this region. The southeast monsoon, the southwest monsoon, the plateau monsoon, and the westerly circulation combine to influence the climate changes in northwest China; at the same time, the thermal and dynamic action of the Qinghai-Tibet Plateau and the changes in the northwest underlying surface can both bring about climate changes 
in this region, rendering the climate problems extremely complicated.

There has been considerable research into the influences of urbanization and the changes in the use of land on regional climate and their influences on regional extreme climate events are mainly realized through changing the surface albedo, ground water evapotranpiration, surface roughness length, and sensible heat flux, and laten heat exchange [27,28]. Zhai et al. [22] find that on the regional scale, the action of changes in land use on extreme climate events and precipitation can even be comparable to the radiation intensity of $\mathrm{CO}_{2}$, indicating that the influence of land-atmosphere interaction brought about by changes in land vegetation cover on extreme climate events is very important. Therefore, when studying the influence factors of extreme weather and climate events, changes in features closely connected with land use, such as land cover and soil moisture, are being attached more and more importance, and their importance has been proved by substantial research. The research of Griffiths et al. [29] into the extreme temperature change in the Asia-Pacific Region indicates that for urbanization sites, the mean value of both maximum and minimum temperatures can increase noticeably, and their standard deviation decrease markedly; for non-urbanization sites, it is mainly changes in their mean value and resultant changes in the maximum and minimum temperatures while the changes in their standard deviation are not obvious. However, past research mainly concentrated on research into climate mean state and seldom on the influence of urbanization and changes in land use on extreme climate events. The influence of the change of underlying surface on extreme climate events is the issue that will deserve the attention of future research into extreme climate events $[5,28]$.

\section{A Prediction of the Situation of Future Extreme Climate Events}

Like mean climate state, the major method of predicting the change brought about in extreme climate events by the increase in emissions of greenhouse gases, is numerical climate model. Numerical simulated experiments conducted by using the Global Climate Model (GCM) have produced considerable achievements [2,26,29]. Famous GCMs are mainly the CCSM3 of the National Center of Atmospheric Research [30], the ECHAM5/ MP1-OM of Max-Planck Institute [31], and the HadCM2/3 of the Haley Center for Climate Prediction and Research [32].

CCSM3, one of the most advanced climate system models in the world, has been widely used in all the fields of ocean and climate research, and it occupies an especially important position in the Fourth IPCC Assessment Report [33]. Since the horizontal resolution of GCMs is usually several hundred kilometers, and description is ob- viously insufficient of mountains and seacoasts, the physical processes of land surface, and mesoscale air currents, it is difficult to simulate the spatial distribution of regional temperatures of China [29] and centers of precipitation. Therefore, dividing the results of prediction of global scale climate simulated with climate models, employing the method of statistic down-scaling or statisticdynamical downscaling to simulate meso- and small-scale regional climate scenarios has become an important means of predicting future climate scenarios worldwide. Studies indicate that a series of results related to climate extremes can be obtained from the prediction results of global climate models by means of downscaling [34].

Since regional climate models (RCM) of high-resolution grid points can very well reflect the surface features that influence local climates and the future laws of vibration of climate itself, and overcome the limitations of GCMs. GCM is considered the best downscaling method to obtain high-resolution information of local climate changes. At present the most widely used is the RegCM of NCAR, which has been employed to carry out simulation study of the United States, Europe, Africa, Australia, East Asia-West Atlantic Area [35,36] is a regional climate model developed and improved by the International Center for Theoretical Physics on the basis of RegCM2 [37] from 2003 to 2004 which is much faster and simpler in calculation and the input and output of data.

With the development of computer technology, RCM has been widely used in the climate simulation of inter decadal change temporal scale and the prediction of climate change (IPCC, 2007). In the past models of the resolution of over $50 \mathrm{~km}$ was used to carry our several months' or even several years' integration. Now models of the resolution of $20 \mathrm{~km}$ or higher resolution are adopted to carry out inter-decade-scale climatic simulation and prediction of climate change [38]. For example, Jason et al. [39], by means of RegCM2, simulated the future time and length of growth season and the frequency and intensity of extreme temperature and precipitation in California; Mizuta by using the extreme indexes defined by Frich et al. [11], analyzed the results of simulating extreme event change in Japan by means of the $20 \mathrm{~km}$ resolution global climatic model. Some effort has gone into applying regional climatic models in China [40]; for example, Shi et al. simulate the extreme climate events in east China by using RegCM3 [41] (resolution: $20 \mathrm{~km}$ ), but not much research has been conducted into the integration simulation of comparatively longer time scale under the background of climate change [42]. Besides, since the temperature simulated by using the global climatic model are systemically low compared with observed value [20], a better method should be worked out to revise the climatic scenarios.

Since the theory structure is same for different air cir- 
culation mode, but they are different on mode boundary set and space resolution etc, which lead to output result is uncertainty [2]. Toward complicated geography and landform in Northwest region and subject to number of driving power influence, so GCM output result can not descript regional climate feature completely, and the value of runoff calculated have a big error [43]. Two method were made including improve GCM mode [40,41] and adopt downscaling, as well as establish regional climate mode (RCM) in order to make up deficiency of GCM at this respect. In spite of both downscaling technology between dynamic downscaling and statistic downscaling method have an argument [44] on which one is better, the dynamic downscaling technology more and more widely is used.

\section{Existing Questions and Study Direction in Future}

In summary, so many achievements were made on extreme climatic events, but it is very difficult to make a compare to different study result due to different defined method, sequence length utilized, space distribution density or different data type, as well as different method for trend inspection etc, and also can't reflect extreme climatic change feature if combined with different research result as one whole. The detect of extreme climatic changes need utilize maturity index and statistical method. The current extreme climatic index exist some defects, so need to continuous to improve according to specific situation in various region. Under the background of climatic changes, the feature which weather factors probability distribution may be change, as result it is more difficult for us to inspect variation of climate limited value, therefore, we need to adopt new mathematical tools to descript the extreme climatic background status correctly. The calculate and analyze about extreme climatic sequence liner trends depend on the selection of time-scale, at the same time, the trends is subject to the influence of extreme limit value, so how to calculate and analyze more correctly the trends, we are waiting for further study.

In addition, mostly research main focus a certain kind of or one category extreme climatic events, but now we lack study and research toward number of kinds or category extreme climatic events in one region. In inspection and influence of climatic changes, as well as those activities performed by government and citizen against climatic changes, we often need know change frequency and intensity totally situation occurred by climatic change in one region or more countries, in order to know about probable response signal of region climate, and comprehensive influence of a number of kind extreme climatic events frequency and intensify generated. In short, the study for extreme climate events and its changes is just only beginning compared to average climate and its changes, so many problems unknown are worthy to discuss and research, also those questions were not being involved in are waiting for us to do further and widely study and research, such as small-scale outburst of extreme climatic events.

\section{Acknowledgements}

This work was supported by the National Natural Science Foundation Project of China (41001020). The authors are grateful to JunFeng $\mathrm{Li}$ and Chao Ming for their help in preparing this article.

\section{REFERENCES}

[1] D. Qin, "Coping with Global Climate Change and Preventing Climate Disasters," Population Resource Environment, Vol. 8, 2007, pp. 5I-53.

[2] IPCC, "Climate Change 2007: The Physical Science Basis. Contribution of Working Group I to the Fourth Assessment Report of the Intergovernmental Panel on Climate Change,” Cambridge University Press, Cambridge, 2001.

[3] R. W. Katz and J. G. Acero, "Sensitivity Analysis of Extreme Precipitation Events," International Journal of Climatology, Vol. 14, No. 9, 1994, pp. 985-999. doi:10.1002/joc.3370140904

[4] D. R. Easterling, L. Evans, P. Ya Groisman, et al., “Observed Variability and Trends in Extreme Climate Events: A Brief Review," Bulletin of the American Meteorological Society, Vol. 1, No. 3, 2000, pp. 417-425.

[5] X. Gao, "An Prediction Study of Climate Extremes in China,” Advances in Climate Extreme Studies, Vol. 3, No. 3, 2007, pp. 162-166.

[6] J. T. Houghton, Y. Ding, D. J. Griggs, et al., "IPCC, Climate Change 2001: The Scientific Basis,” Cambridge University Press, Cambridge, 2001.

[7] F. Ren and P. Zhai, "An Analysis of the Changes in the Climate Extremes Between 1951 1990,” Atmospheric Science, Vol. 22, No. 2, 1998, pp. 217-227.

[8] P. Zhai and F. Ren, "A Trend Test of the Changes in China's Precipitation Extremes,” Journal of Meteorology, Vol. 57, No. 2, 1999, pp. 208-216.

[9] L. V. Alexander, X. Zhang, T. C. Peterson, et al., "Global Observed Changes in Daily Climate Extremes of Temperature and Precipitation,” Journal of Geophysical Research, Vol. 111, No. D5, 2006.

[10] T. C. Peterson, C. Folland, G. Gruze, et al., "Report on the Activities of the Working Group on Climate Change Detecton and Related Rapporteurs, 1998-2001,” World Meteorological Organization, 2001, pp. 1-143.

[11] P. Frich, L. V. Alexander, P. Della-Marta, et al., “Observed Coherent Changes in Climatic Extremes during the Second Half of the Twentieth Century," Climate Research, Vol. 19, No. 3, 2002, pp. 193-212. doi:10.3354/cr019193

[12] P. Zhai and X. Pan, “Changes in North China's Tempe- 
rature and Precipitation in the Last 50 Years,” Journal of Geography, Vol. 58, 2003, pp. 1-10.

[13] P. D. Jones, E. B. Horton, C. K. Folland, et al., "The Use of Indices to Identity Changes in Climatic Extremes," Climatic Change, Vol. 42, No. 1, 1999, pp. 131-149. doi:10.1023/A:1005468316392

[14] G. Ren and Y. Chen, "The Definition and an Analysis of the Trends in Integrated Climate Extremes," Meteorological and Environmental Studies, Vol. 15, No. 4, 2010, pp. 354-364.

[15] T. R. Karl, R. W. Knight, D. R. Easterling, et al., "Indices of Climate Change for the United States," Bulletin of the American Meteorological Society, Vol. 77, No. 2, 1996, pp. 279-292.

doi:10.1175/1520-0477(1996)077<0279:IOCCFT>2.0.C $\underline{\mathrm{O} ; 2}$

[16] K. L. Gleason, J. H. Lawrimore, D. H. Levinson, et al., “A Revised US Climate Extremes Index," Journal of Climate, Vol. 21, No. 10, 2008, pp. 2124-2137. doi:10.1175/2007JCLI1883.1

[17] Y. Ding, C. Zheng and H. Shen, "The Progress of the Study of Climate Extremes,” Desert and Oasis Meteorology, Vol. 2, No. 6, 2008, pp. 1-6.

[18] G. Choi, D. Collins, G. Y. Ren, et al., "Changes in Means and Extreme Events of Temperature and Precipitation in the Asian-Pacific Network Region, 1955-2007,” International Journal of Climatofogy, Vol. 29, No. 13, 2009, pp. 1906-1925.

[19] M. Brunetti, L. Buffoni and F. Mangianti, “Temperature, Precipitation and Extreme Events during the Last Century in Italy," Global and Planetary Change, Vol. 40, No. 1-2, 2004, pp. 1-49. doi:10.1016/S0921-8181(03)00104-8

[20] Z. X. Xu, Y. N. Chen and J. Y. Li, "Impact of Climate Change on Water Resources in the Tarim River Basin," Water Resources Management, Vol. 18, No. 5, 2004, pp. 439-458. doi:10.1023/B:WARM.0000049142.95583.98

[21] Z. Jiang, Y. Ding and W. Chen, "A Prediction of the Precipitation Extremes in 21st Century China," Advances in Cliamte Change Research, Vol. 3, No. 4, 2007, pp. 202207.

[22] P. M. Zhai, X. B. Zhang, H. Wan, et al., "Trends in Total Precipitation and Frequency of Daily Precipitation Extremes over China,” Journal of Climate, Vol. 18, No. 7, 2005, pp. 1096-1108. doi:10.1175/JCLI-3318.1

[23] Y. J. Ding, S. Y. Liu, J. Li, et al., "The Retreat of Glaciers in Response to Recent Climate Warming in Western China," Annals of Glaciology, Vol. 43, No. 1, 2006, pp. 97-105. doi:10.3189/172756406781812005

[24] L. O. Mearns, R. W. Katz and S. H. Schneider, "Extreme High-Temperature Events in Their Probalities Changes in Mean Temperature," Journal of Climate and Applied Meteorology, Vol. 23, No. 2, 1984, pp. 1601-1613. doi:10.1175/1520-0450(1984)023<1601:EHTECI >2.0.C $\mathrm{O} ; 2$

[25] Z. W. Yan and C. Yang, "Geographic Patterns of Extreme Climate Changes in China during 1951-1997," Climatic and Environmental Research, Vol. 5, No. 3, 2000, pp. 2672-372.
[26] Y. Wang, P. Zhai and H. Tian, "The Characteristics of the Change in High Temperatures in South China in the Past 40 Years and the High Temperatures of 2003," Meteoroloy, Vol. 32, No. 10, 2006, pp. 27-33.

[27] N. Zeng, R. E. Dickinson and X. Zeng, "Climate Impact of Amazon Deforestation-A Mechanistic Model Study,” Journal of Climate, Vol. 9, No. 4, 1996, pp. 859-883. doi:10.1175/1520-0442(1996)009<0859:CIOADM >2.0.C $\underline{\mathrm{O} ; 2}$

[28] Y. Hu, W. Dong and Y. He, "Advances in the Study of Early 2lst Century Climate Extremes," Advances in Earth Science, Vol. 10, 2007, pp. 1066-1075.

[29] T. Zhou and R. Yu, “Twentieth Century Surface Air Temperature over China and the Globe Simulated by Coupled Climate Models,” Journal of Climate, Vol. 19, No. 22, 2006, pp. 5843-5858. doi:10.1175/JCLI3952.1

[30] M. Vertenstein, T. Craig, T. Henderson, et al., "CCSM3 User's Guide," National Center for Atmospheric Research, Boulder, 2004.

[31] M. A. Giorgetta, G. P. Brasseur, E. Roeckner, et al., "Preface to Special Section on Climate Models at the Max Planck Institute for Meteorology," Journal of Climate, Vol. 19, No. 16, 2006, pp. 3769-3770. doi:10.1175/JCLI9023.1

[32] C. Gordon, C. Cooper, C. A. Senior, et al., "The Simulation of SST, Seaice Extents and Ocean Heat Transports in a Version of the Hadley Centre Coupled Model without Flux Adjustments,” Climate Dynamics, Vol. 16, No. 2, 2000, pp. 147-168. doi:10.1007/s003820050010

[33] C. H. Wang, G. D. Cheng, A. J. Deng and W. J. Dong, "Numerical Simulation on Climate Effects of FreezingThawing, Processes Using CCM3," Science in Clod Arid Regions, Vol. 1, No. 1, 2008.

[34] J. Haughton, "Contribution of Working Group I to the Second Assessment Report of IPCC,” Cambridge University Press, Cambridge, 1996.

[35] F. Giorgi, M. R. Marinucci and G. T. Bates, "Development of a Second-Generation Regional Climate Model (RegCM2). Part I: Boundary-Layer and Radiative Transfer Processes," Monthly Weather Review, Vol. 121, No. 10, 1993, pp. 2794-2813.

[36] J. S. Boyle, "Sensitivity of Dynamical Quantities to Horizontal Resolution for a Climate Simulation Using the ECMWF (Cycle33) Model,” Journal of Climate, Vol. 6, No. 5, 1993, pp. 796-815.

doi:10.1175/1520-0442(1993)006<0796:SODQTH $>2.0 . C$ $\underline{\mathrm{O} ; 2}$

[37] X. Li, Z. Ji, H. Wu, et al., "The Characteristics of Distribution and Interdecadal Differences of Tempereature and Precipitation Extremes of the Recent 40 Years in China," Journal of Tropical Meteorogy, Vol. 22, No. 6, 2006, pp. 618-624.

[38] H. Yang, Y. Xu, L. Zhang, et al., “Advances in the Study of the Simulation Climate Change of the Mean and Extreme Climate Changes under the Background of SRES A2,” Advances in Climate Change, Vol. 6, No. 3, 2010, pp. 157-163.

[39] A. Boone, et al., “The Rhone-Aggregation Land Surface 
Scheme Intercomparison Project: An Overview,” Journal of Climate, Vol. 17, No. 1, 2004, pp. 187-208. doi:10.1175/1520-0442(2004)017<0187:TRLSSI >2.0.CO ;2

[40] Y. Xu, Z. Zhao, Y. Luo, et al., "Climate Change Projections for the 21st Century by the NCC/IAP T63 Model with SRES Scenarios," Acta Meteorological Sinica, Vol. 19, No. 4, 2005, pp. 407-417.

[41] J. S. Pal, F. Giogi, X. Q. Bi, et al., "Regional Climate Moeling for the Developing World: The ICTP RegCM3 and RegC-NET," Bulletin of the American Meteorological Society, Vol. 88, No. 9, 2007, pp. 1395-1409.

[42] B. A. Boville, "Sensitivity of Simulated Climate to Model
Resolution,” Journal of Climate, Vol. 4, No. 5, 1991, pp. 469-485. doi:10.1175/1520-0442(1991)004<0469:SOSCTM>2.0.C $\underline{\mathrm{O} ; 2}$

[43] X. Gao, Y. Shi, R. Song, et al., "Reduction of Future Monsoon Precipitation over China: Comparison between a High Resolution RCM Simulation and the Driving GCM,” Meteorology and Atmospheric Physics, Vol. 100, No. 1, 2008, pp. 73-86.

[44] S. Tripathi, V. V. Srinivas and R. S. Nanjundiah, "Downscaling of Precipitation for Climate Change Scenarios: A Support Vector Machine Approach,” Journal of Hydrology, Vol. 330, No. 1-2, 2006, pp. 621-640. 